\title{
Chirality Effects on the IRMPD Spectra of Basket Resorcinarene/Nucleoside Complexes
}

Antonello Filippi, ${ }^{[a]}$ Caterina Fraschetti, ${ }^{[a]}$ Susanna Piccirillo, ${ }^{[b]}$ Flaminia Rondino, ${ }^{[a]}$ Bruno Botta, ${ }^{[\mathrm{a}]}$ Ilaria D' Acquarica, ${ }^{[\mathrm{a}]}$ Andrea Calcaterra, ${ }^{[\mathrm{a}]}$ and Maurizio Speranza*[a]

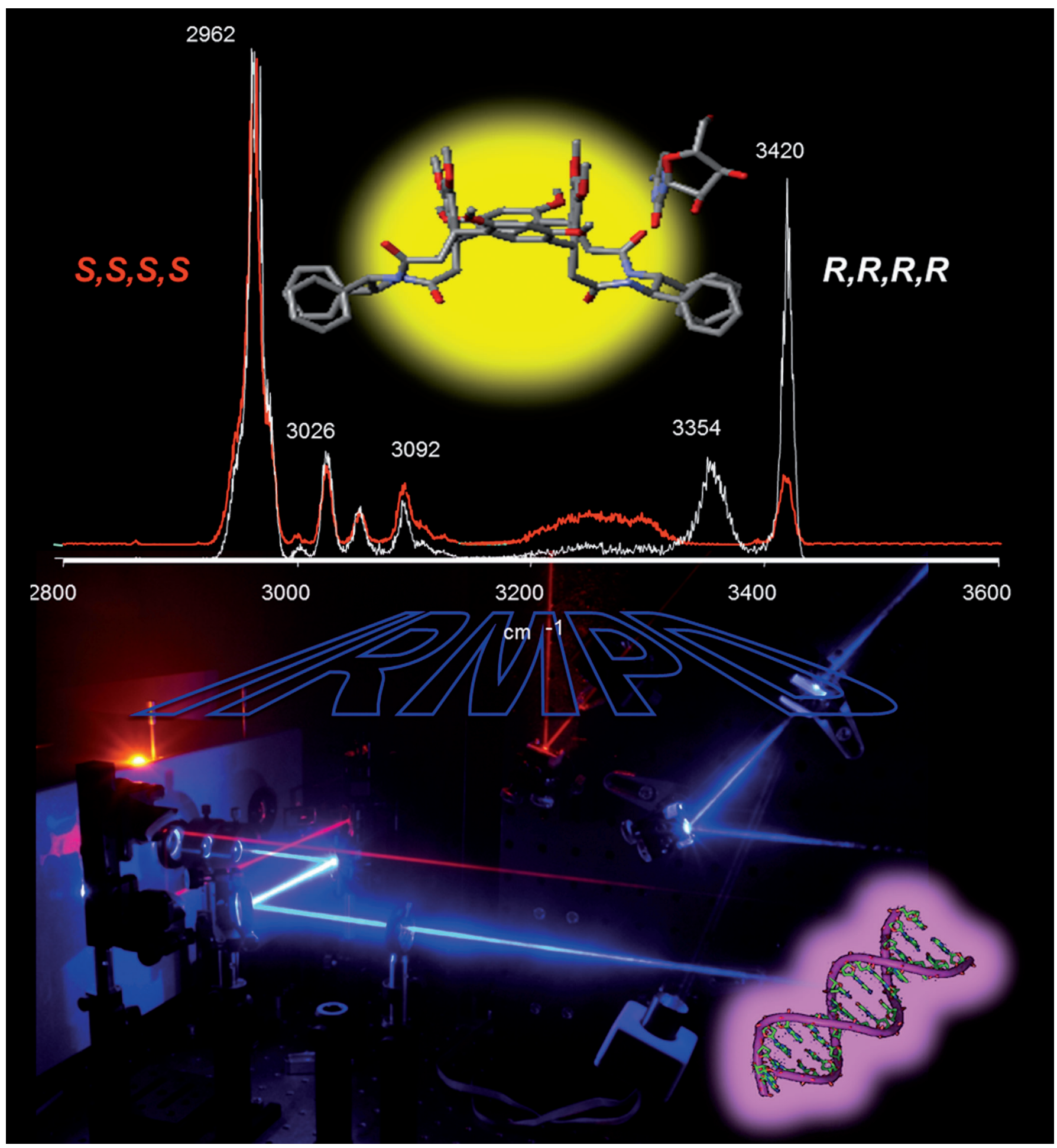




\begin{abstract}
The IRMPD spectra of the ESI-formed proton-bound complexes of the $R, R, R, R$ - and $S, S, S, S$-enantiomers of a bis(diamido)-bridged basket resorcin[4]arene ( $\mathbf{R}$ and $\mathbf{S}$ ) with cytosine (1), cytidine (2), and cytarabine (3) were measured in the region 2800 $3600 \mathrm{~cm}^{-1}$. Comparison of the IRMPD spectra with the corresponding ONIOM (B3LYP/6-31(d):UFF)-calculated absorption frequencies allowed the assessment of the vibrational modes that are responsible for the observed spectroscopic features. All of
\end{abstract}

the complexes investigated, apart from $[\mathbf{R} \cdot \mathrm{H} \cdot 3]^{+}$, showed similar IRMPD spectra, which points to similar structural and conformational landscapes. Their IRMPD spectra agree with the formation of several isomeric structures in the ESI source, wherein the N(3)-protonated guest establishes noncovalent interactions with the host amidocar-

Keywords: chirality $\cdot$ IRMPD spectroscopy $\cdot$ noncovalent interactions • nucleosides $\cdot$ resorcinarenes bonyl groups that are either oriented inside the host cavity or outside it between one of the bridged side-chains and the upper aromatic nucleus. The IRMPD spectrum of the $[\mathbf{R} \cdot \mathrm{H} \cdot \mathbf{3}]^{+} \mathrm{com}-$ plex was clearly different from the others. This difference is attributed to the effect of intramolecular hydrogenbonding interactions between the $\mathrm{C}\left(2^{\prime}\right)-\mathrm{OH}$ group and the aglycone oxygen atom of the nucleosidic guest upon repulsive interactions between the same oxygen atom and the aromatic rings of the host.

\section{Introduction}

Enantioselectivity implies that the reaction of a chiral receptor with a chiral molecule preferentially yields one product enantiomer over the other. The nature of the enantioselectivity is one of the most fundamental and provocative problems in stereochemistry and its solution can only be attempted after disentangling all of the factors involved, including: 1) the interference of the reaction environment in the receptor/molecule encounters and their evolution into the products; 2) the specific configuration-dependent interactions in the unsolvated or partially solvated receptor/molecule complex; and 3) the orientation of the functionalities in the receptor/molecule adducts that affect their reaction efficiency. ${ }^{[1,2]}$

In recent years, mass spectrometry has been a powerful means for investigating the stability and reactivity of chiral complexes in the gas phase, that is, in the absence of solvation and ion-pairing phenomena. ${ }^{[3-24]}$ Positive information on the structure and the conformation of covalently bonded diastereomeric ions ${ }^{[25]}$ and their metal adducts ${ }^{[26,27]}$ has been obtained after the recent introduction of a very powerful and sensitive technique, namely the variable-wavelength infrared multiple photon dissociation (IRMPD) spectroscopy. ${ }^{[28-36]}$ In contrast, the IRMPD-based stereochemical investigation of noncovalent chiral-ion/chiral-molecule complexes has drawn much less attention. ${ }^{[37,38]}$ The major difficulty in these studies arises from the fact that their diastereomeric complexes are all held together by the same strong electrostatic interactions (e.g., proton and hydrogen-bonding) and

[a] Prof. A. Filippi, Dr. C. Fraschetti, Prof. F. Rondino, Prof. B. Botta, Dr. I. D'Acquarica, Dr. A. Calcaterra, Prof. M. Speranza Dipartimento di Chimica e Tecnologie del Farmaco Università di Roma "La Sapienza”, 00185 Roma (Italy)

[b] Prof. S. Piccirillo

Dipartimento di Scienze e Tecnologie Chimiche Università di Roma “Tor Vergata”, 00133 Rome (Italy)

Supporting information for this article is available on the WWW under http://dx.doi.org/10.1002/chem.201200614. any difference in their structure and stability is the result of much-weaker factors, such as dispersion or repulsion interactions, charge transfer, and conformational effects. The consequence is that noncovalent ion/molecule diastereomers often exhibit the same IRMPD spectroscopic features, sometimes with small differences in the band intensities. ${ }^{[38]}$

Herein, we report diastereomeric proton-bound receptor/ molecule complexes that show IRMPD spectra with clearly different signatures. These findings reveal an unprecedented effect of chirality on strong electrostatic interactions in gaseous ionic complexes.

As a chiral receptor, we chose the $R, R, R, R$ - and the $S, S, S, S$-enantiomers of the bis(diamido)-bridged basket resorcin[4] arene (Figure 1; henceforth denoted as $\mathbf{R}$ and $\mathbf{S}$, re-
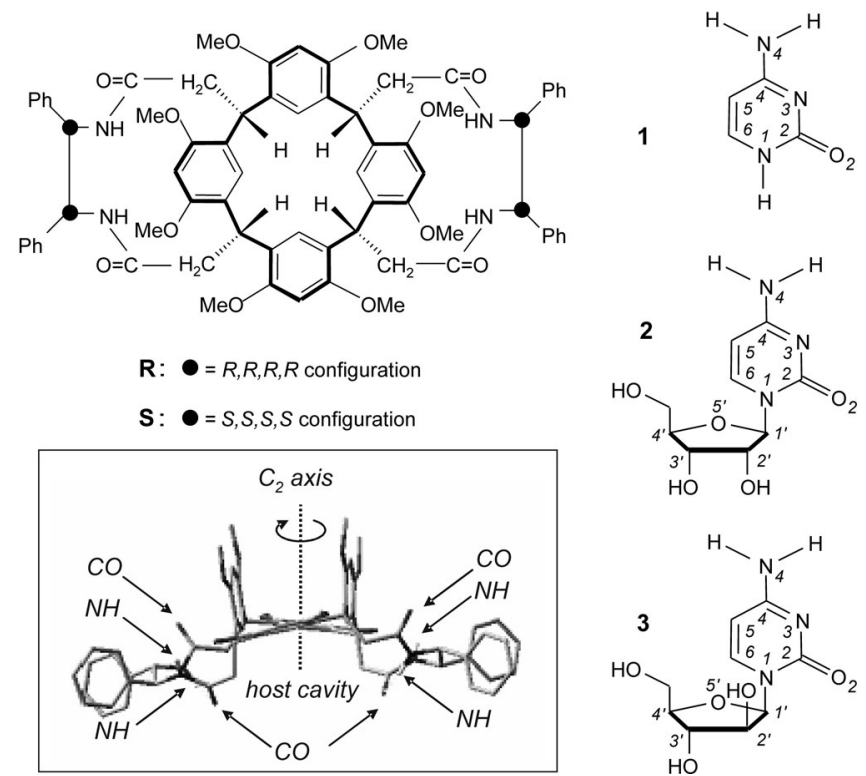

Figure 1. Structures of the flattened-cone bis(diamido)-bridged basket resorcin[4] arenes $\mathbf{R}$ and $\mathbf{S}$ and of cytosine (1), cytidine (2), and cytarabine (3). Inset: structure of the $\mathbf{R}$ enantiomer in its most-stable "openwinged" conformation. ${ }^{[39]}$ 
spectively) in the flattened cone conformation. Cytidine (2) and its epimer cytarabine (3) were used as chiral guests because of their ability to establish stable proton bonds with the amidocarbonyl groups on the basket resorcin[4]arene. ${ }^{[39-41]}$ For comparison, the study was also extended to cytosine (1), which was used as a simplified achiral model of compounds 2 and 3. For the sake of clarity, the functional groups that belong to the host will be given in italic.

As shown in the inset of Figure 1, the most-stable "openwinged" structure of the flattened-cone $\mathbf{R}$ and $\mathbf{S}$ hosts ${ }^{[39]}$ displays a slight distortion of the resorcin[4]arene nucleus, presumably owing to the stereogenic centers (Figure 1, black dots) and to the resulting asymmetric orientation of the bridged side-chains (the wings) that hold two face-to-face phenyl rings. Each wing is connected to the rest of the host frame through two adjacent $\mathrm{NH}-\mathrm{CO}$ moieties whose carbonyl groups point either inside, or outside the host cavity (Figure 1). The amidocarbonyl groups are connected to the adjacent $\mathrm{NH}$ group that was oriented in the same direction. An intramolecular hydrogen bond (henceforth denoted as $N H \cdots O C)$ is formed within each wing, between the $C O$ and $\mathrm{NH}$ groups that are oriented inside the host cavity. The distance between the $\mathrm{NH}$ and $\mathrm{CO}$ groups that are oriented away from the host cavity is so large that a similar interaction is prevented.

\section{Results}

IRMPD spectra: The vibrational spectra of the ESI-formed proton-bound complexes were obtained by using IRMPD spectroscopy. This technique is based on a multistep absorption process followed by the fast intramolecular redistribution of the excess vibrational energy (IVR). If the IR photons are in resonance with an IR-active vibrational mode of the complex, energy can be transferred and, after several absorption steps, the ions undergo fragmentation by the formal loss of the nucleosidic guest. By recording the intensity of the residual fragment, that is, the protonated host $\left(I_{F}\right)$ whilst varying the wavelength of the IR photons, an IRMPD spectrum is obtained. The IRMPD-fragmentation efficiency is defined as $-\log \left[I_{F} /\left(I_{P}+I_{F}\right)\right]$, where $I_{P}$ is the intensity of the parent complex. ${ }^{[42]}$

Figure 2 shows the IRMPD spectrum of $[\mathbf{R} \cdot \mathrm{H} \cdot \mathbf{1}]^{+}$and Figure 3 shows the IRMPD spectra of the diastereomeric complexes with guests $\mathbf{2}$ and $\mathbf{3}$. The common features in all of these spectra are the packet of sharp resonances from about 2960 to $3100 \mathrm{~cm}^{-1}$ and more or less intense broad structured resonances in the range $3100-3300 \mathrm{~cm}^{-1}$. Moreover, all of the IRMPD spectra display a sharp peak at $3420 \mathrm{~cm}^{-1}$ (with compound 3) or at $3425 \mathrm{~cm}^{-1}$ (with compounds $\mathbf{1}$ or $\mathbf{2}$ ). The same signal is accompanied in the spectrum of $[\mathbf{R} \cdot \mathrm{H} \cdot \mathbf{1}]^{+}$by an intense peak at $3479 \mathrm{~cm}^{-1}$ and a tiny peak at $3460 \mathrm{~cm}^{-1}$ (Figure 2). Only some differences in the signal shape and intensity are observed between the diastereoisomers $[\mathbf{R} \cdot \mathrm{H} \cdot 2]^{+}$and $[\mathbf{S} \cdot \mathrm{H} \cdot \mathbf{2}]^{+}$in the region 3100 $3300 \mathrm{~cm}^{-1}$ (Figure $3 \mathrm{a}, \mathrm{b}$ ). In contrast, the spectrum of

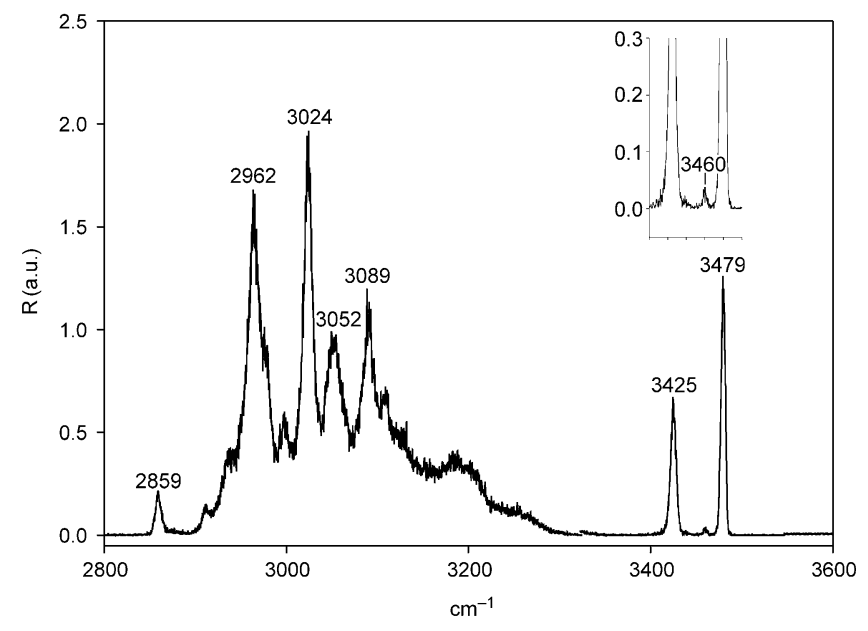

Figure 2. IRMPD spectra of the ESI-formed $[\mathbf{R} \cdot \mathrm{H} \cdot \mathbf{1}]^{+}$; the irradiation time was kept constant over the whole frequency range.

$[\mathbf{R} \cdot \mathrm{H} \cdot 3]^{+}$also displays a pronounced signal at $3354 \mathrm{~cm}^{-1}$, which is conspicuously absent in the spectrum of $[\mathbf{S} \cdot \mathrm{H} \cdot \mathbf{3}]^{+}$ (Figure 3c,d).

Computational results: The presence of several basic centers in the flexible nucleosides and the large size of their protonbound complexes with the basket resorcin[4]arene makes a full exploration of the potential-energy surface of their corresponding proton-bound complexes extremely challenging. Therefore, to determine their equilibrium geometry and harmonic vibrational frequencies, we decided to adopt a multistep strategy. First, the relative proton affinities (PAs) of the most-basic n-centers of the nucleoside were calculated by using the Lee-Young-Parr (B3LYP $)^{[43,44]}$ correlation functional and the $6-311++\mathrm{G}(\mathrm{d}, \mathrm{p})$ basis set, as implemented in the Gaussian 03 set of program suites. ${ }^{[45]}$ At this level of theory, the most basic centers of compounds $\mathbf{1}, \mathbf{2}$, and $\mathbf{3}$ are their $\mathrm{N}(3)$ and $\mathrm{O}(2)$ atoms (for the numbering of the nucleoside atoms, see Figure 1). The N(3) center of compound 1 was less basic than the $\mathrm{O}(2)$ by $0.2 \mathrm{kcal} \mathrm{mol}^{-1}$, which is in good agreement with previous estimates. ${ }^{[46,47]}$ The PA gap between the same centers in compounds $\mathbf{2}$ and $\mathbf{3}$ appreciably depends upon their specific sugar puckering and orientation relative to aglycone. Extensive computational study of this dependence indicated that the $\mathrm{N}(3)$ center of compound $\mathbf{2}$ is always more basic than the $\mathrm{O}(2)$ center by at least $0.2 \mathrm{kcal}$ $\mathrm{mol}^{-1}$ and that this gap increases to over $1.7 \mathrm{kcal} \mathrm{mol}^{-1}$ for compound 3. ${ }^{[48]}$

The second step involved the notion that Monte Carlo molecular mechanics (MCMM) docking and constant-temperature MD simulation of analogous proton-bound complexes with the basket resorcin[4]arene converged unambiguously towards several stable local minima in which the guest is either located on the lower rim of the host (henceforth denoted as "in") or outside its cavity but always proton-bonded to the $C O$ groups (henceforth denoted as "out"; Figure 4). ${ }^{[49]}$ 

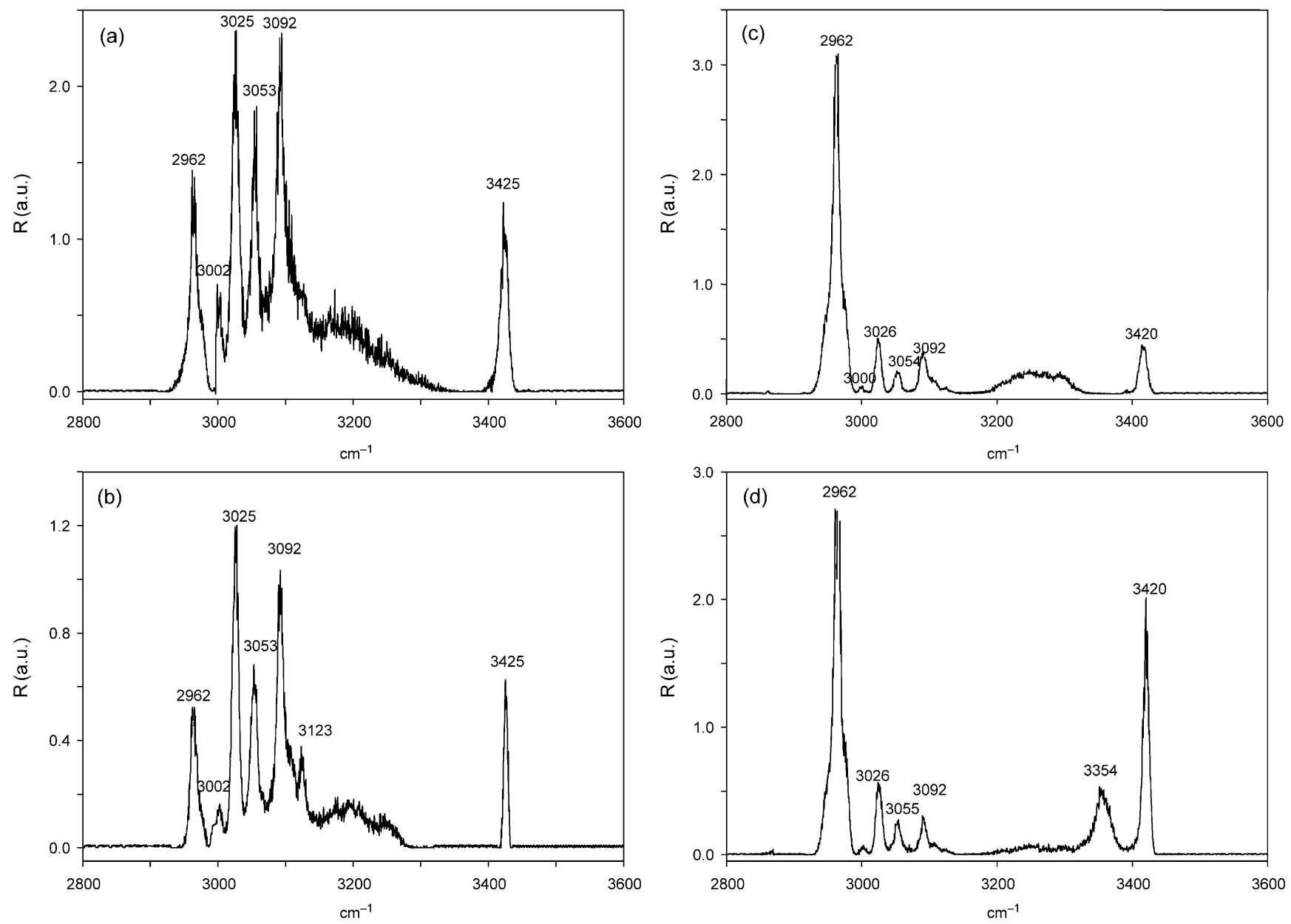

Figure 3. IRMPD spectra of the ESI-formed diastereomeric complexes $[\mathbf{R} \cdot \mathrm{H} \cdot \mathbf{2}]^{+}(\mathrm{a}),[\mathbf{S} \cdot \mathrm{H} \cdot \mathbf{2}]^{+}(\mathrm{b}),[\mathbf{R} \cdot \mathrm{H} \cdot \mathbf{3}]^{+}(\mathrm{c})$, and $[\mathbf{S} \cdot \mathrm{H} \cdot \mathbf{3}]^{+}(\mathrm{d})$. The irradiation time was kept constant over the whole frequency range.

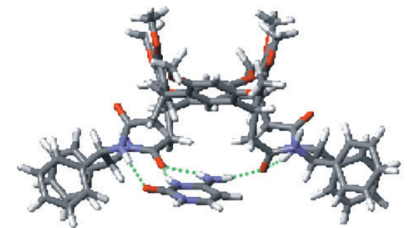

(in)

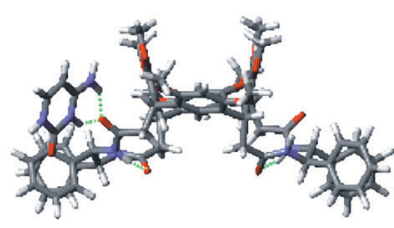

(out)

Figure 4. Typical "in" and "out" structures of $[\mathbf{R} \cdot \mathrm{H} \cdot \mathbf{1}]^{+}$

Assuming similar "in" and "out" arrangements for the $\mathrm{N}(3)$ - and $\mathrm{O}(2)$-protonated nucleosides, we calculated the optimized geometry, relative stability, and the harmonic vibrational frequencies of their corresponding complexes at the ONIOM (B3LYP/6-31(d):UFF) level of theory. The optimized structures of the $[\mathbf{R} \cdot \mathrm{H} \cdot \mathbf{1}]^{+},[\mathbf{R} \cdot \mathrm{H} \cdot 2]^{+},[\mathbf{S} \cdot \mathrm{H} \cdot 2]^{+}$, $[\mathbf{S} \cdot \mathrm{H} \cdot \mathbf{3}]^{+}$, and $[\mathbf{R} \cdot \mathrm{H} \cdot \mathbf{3}]^{+}$regioisomers are shown in the Supporting Information, Figures S1-S5, respectively. In all cases, thermochemical calculations indicated a distinct preference of their guests to be protonated at their N(3) centers, rather than at their $\mathrm{O}(2)$ centers, when interacting with the host amidocarbonyl moieties.

This conclusion is further supported by better correlation between the experimental spectra of a given complex and the calculated harmonic vibrational frequencies of its most stable N(3)-protonated structure (e.g., see the Supporting Information, Figure S6). Therefore, from now on, our discussion will be restricted to the ONIOM (B3LYP/631(d):UFF)-calculated structures and the harmonic frequencies of the complexes that involve the N(3)-protonated guests (see Tables 1-5 and the Supporting Information, Figure $\mathrm{S} 1-\mathrm{S} 5)$.

\section{Discussion}

The experimental IRMPD spectra (Figure 2 and Figure 3) were invariably characterized by sharp signals that are accompanied by very broad features. It is a well-known feature of the IRMPD spectra of noncovalent adducts that contain $\mathrm{NH}$ and $\mathrm{OH}$ hydrogen-bond donors that their stretching vibrations can be more or less red-shifted and broadened, depending upon their relevant dissociation threshold. ${ }^{[34,46,47,50-56]}$ The broad resonances at $3100-3300 \mathrm{~cm}^{-1}$ 
could be a signature of these effects. However, it was also possible that the same broad features arise from the co-existence of several different conformers of the complexes in the ESI source.

Figure 2 and Figure 3 also show that the relative intensity of the IRMPD peaks do not always reflect the relative intensity of the calculated absorption frequencies of the various structures (Tables 1-5). In a few cases, several of the calculated frequencies are even missing in the IRMPD spectra. The intensity of the experimental IRMPD signals is determined by the probability of depositing enough excess energy into the specific bond(s) that is involved in complex fragmentation. This probability does not only depend on the efficiency of the resonant photon absorption, but also on the efficiency of the IVR process, as well as on the dissociation energy barrier. ${ }^{[56]}$ Thus, it is possible that the resonant absorption by a given IR-active vibrational mode in a complex does produce a signal with a relative intensity that is different from the corresponding calculated linear IR-absorption intensity.

The sharp resonances at $2960-3100 \mathrm{~cm}^{-1}$ in all of the spectra (Figure 2 and Figure 3) are essentially attributed to the $\mathrm{C}-\mathrm{H}$ stretching modes in the host and will not be discussed any further. Concerning the spectrum of $[\mathbf{R} \cdot \mathrm{H} \cdot \mathbf{1}]^{+}$, the unresolved bands at $3100-3300 \mathrm{~cm}^{-1}$ cannot be taken as a signature of the "in" and "out" structures (Table 1) because their $\mathrm{N}(3)-$ $\mathrm{H} \cdots O C\left(v_{1}\right), \mathrm{N}(4)-\mathrm{H} \cdots O C N-H$ $\left(v_{2}\right)$, and symm $\mathrm{H}-\mathrm{N}(4)-$ $\mathrm{H} \cdots \mathrm{OC}\left(v_{3}\right)$ stretching vibrations all fall in the same broad range. A similar conclusion is reached with regards to the intense sharp resonance at $3479 \mathrm{~cm}^{-1}$, which is attributed to the strong $\mathrm{N}(1)-\mathrm{H}$ stretching $\left(v_{7}\right)$ of cytosine in $[\mathbf{R} \cdot \mathrm{H} \cdot \mathbf{1}]^{+} .{ }^{[46,47]}$ As expected, this band is absent in the spectra in Figure 2 and Figure 3.

In contrast, the small IRMPD peak at $3460 \mathrm{~cm}^{-1}$ and the intense signal at $3425 \mathrm{~cm}^{-1}$ are exclusively assigned to the in-1 structure, because it corresponds to the coordinated $\mathrm{N}^{-}$ $H \cdots O C \quad\left(v_{6}\right)$ and $N-H \cdots \mathrm{OC}$ stretches $\left(v_{5}\right.$; see the $i n-1$ structure in Figure 4 and the spectrum in the Supporting Information, Figure S6), respectively. A similar $v_{5}$ mode is clearly prevented in the out 1 and out2 regioisomers (e.g., see the out-2 structure in Figure 4 and the spectrum in the Supporting stable $[\mathbf{R} \cdot \mathbf{H} \cdot \mathbf{1}]^{+}$structures. stable $[\mathbf{S} \cdot \mathrm{H} \cdot \mathbf{2}]^{+}$structures.
Information, Figure S6). We concluded that a significant fraction of ESI-formed complex $[\mathbf{R} \cdot \mathrm{H} \cdot \mathbf{1}]^{+}$had the in-1 structure, although the occurrence of other regioisomers, that is, out- 1 and out-2, could not be excluded. It should be noted, in this context, that no appreciable signals are observed around 3349 or $3525 \mathrm{~cm}^{-1}$ (Figure 2), which could be assigned to the strong asymm $\mathrm{H}-\mathrm{N}(4)-\mathrm{H} \cdots O C$ stretch $\left(v_{4}\right.$; Table 1). Possible reasons for these findings have been discussed above.

The diastereomeric complexes $[\mathbf{R} \cdot \mathrm{H} \cdot 2]^{+}$and $[\mathbf{S} \cdot \mathrm{H} \cdot \mathbf{2}]^{+}$ show almost-identical IRMPD spectra, except for some differences in the peak shape and intensity (Figure $3 a, b$ ). Apart from the obvious absence of the $v_{7}$ signal, the spectra of $[\mathbf{R} \cdot \mathbf{H} \cdot \mathbf{2}]^{+}$and $[\mathbf{S} \cdot \mathrm{H} \cdot \mathbf{2}]^{+}$are very similar to that of $[\mathbf{R} \cdot \mathrm{H} \cdot \mathbf{1}]^{+}$. Indeed, they both exhibit a pronounced signal at $3425 \mathrm{~cm}^{-1}$, which is attributed to the $v_{5}$ stretch in the corresponding in1 structure. This assignment is supported by the fact that the in-1 $[\mathbf{S} \cdot \mathbf{H} \cdot \mathbf{2}]^{+}$structure is the most stable (Table 2). The same could not be said for the $[\mathbf{R} \cdot \mathrm{H} \cdot \mathbf{2}]^{+}$diastereomer, for which out-1 is the most stable structure (Table 3 ). The formation and detection of structures other than the most stable ones is by no means unusual in ESI-MS. It may happen that aggregates that are not stable in solution are formed in the ESI microdroplets and released in the gas

Table 1. Experimental and ONIOM (B3LYP/6-31(d):UFF)-calculated vibrational frequencies for the most-

\begin{tabular}{|c|c|c|c|c|c|}
\hline $\begin{array}{l}\text { Experiment } \\
{\left[\mathrm{cm}^{-1}\right]}\end{array}$ & \multicolumn{3}{|c|}{$\begin{array}{l}\text { ONIOM (B3LYP/6-31(d):UFF)-calcd frequencies } \\
\qquad\left[\mathrm{cm}^{-1}\right]^{[\mathrm{a}]}\end{array}$} & Mode description $^{[\mathrm{b}]}$ & Symbol \\
\hline \multirow[t]{4}{*}{$3100-3300$ (broad) } & 3129 (vs) & 3090 (vs) & $3158(\mathrm{~s})$ & $\mathrm{N}(3)-\mathrm{H} \cdots O C$ & $v_{1}$ \\
\hline & & 3188 (vs) & 3187 (vs) & $\mathrm{N}(4)-\mathrm{H} \cdots O C N-H^{[\mathrm{d}]}$ & $v_{2}$ \\
\hline & 3179 (vs) & 3261 (vs) & 3226 (vs) & symm $\mathrm{H}-\mathrm{N}(4)-\mathrm{H} \cdots O C$ & $v_{3}$ \\
\hline & 3349 (vs) & $3527(w)$ & $3523(w)$ & asymm $\mathrm{H}-\mathrm{N}(4)-\mathrm{H} \cdots O C$ & $v_{4}$ \\
\hline 3425 (sharp) & $3422(\mathrm{~s})$ & & & $N-H \cdots \mathrm{OC}^{[\mathrm{d}]}$ & $v_{5}$ \\
\hline 3460 (sharp) & $3452(\mathrm{vw})$ & $3385(w)$ & $3384(w)$ & $N-H \cdots O C^{[\mathrm{d}]}$ & $v_{6}$ \\
\hline \multirow[t]{3}{*}{3479 (sharp) } & 3466 (s) & $3462(w)$ & $3463(w)$ & $\mathrm{N}(1)-\mathrm{H}$ & $v_{7}$ \\
\hline & 3478 (vw) & 3488 (vw) & 3487 (vw) & \multirow{2}{*}{$N-H^{[\mathrm{e}]}$} & \multirow{2}{*}{$v_{8}$} \\
\hline & 3498 (vw) & $3506(\mathrm{vw})$ & $3505(\mathrm{vw})$ & & \\
\hline
\end{tabular}

[a] Scaled by 0.961 , absorption intensity: very weak (vw), weak (w), strong (s), and very strong (vs). [b] The groups that belong to the host are shown in italic; the predominant stretching mode is denoted by the hyphens(s). [c] Relative $\Delta H_{300}$ values are given in parentheses and are in $\mathrm{kcal} \mathrm{mol}^{-1}$. [d] The $\mathrm{N}-\mathrm{H}$ group is oriented inside the host cavity. [e] The $\mathrm{N}-\mathrm{H}$ group is oriented outside the host cavity.

Table 2. Experimental and ONIOM (B3LYP/6-31(d):UFF)-calculated vibrational frequencies for the most-

\begin{tabular}{|c|c|c|c|c|c|c|}
\hline $\begin{array}{l}\text { Experiment } \\
{\left[\mathrm{cm}^{-1}\right]}\end{array}$ & $\begin{array}{r}\text { ONI } \\
\text { in-1 }(5.1)^{[\mathrm{c}]}\end{array}$ & $\begin{array}{l}\text { M (B3LYP/6 } \\
\text { in-2 }(13.0)^{[\mathrm{c}]}\end{array}$ & $\begin{array}{l}31(\mathrm{~d}): \mathrm{UFF})-\mathrm{ca} \\
\text { out }-1(10.3)^{[\mathrm{c}]}\end{array}$ & $\begin{array}{l}\text { cd frequencies } \\
\text { out }-2(12.0)^{[\mathrm{c}]}\end{array}$ & $\begin{array}{l}\left.\mathrm{cm}^{-1}\right]^{[\mathrm{a}]} \\
\text { out }-3(18.6)^{[\mathrm{c}]}\end{array}$ & $\begin{array}{c}\text { Mode } \\
\text { description }^{[b]}\end{array}$ \\
\hline \multirow[t]{4}{*}{$3100-3300$ (broad) } & 3165 (vs) & 3276 (s) & $3170(\mathrm{~s})$ & 3172 (vs) & 3177 (s) & $v_{1}$ \\
\hline & & & $3230(\mathrm{~s})$ & 3198 (vs) & 3212 (vs) & $v_{2}$ \\
\hline & 3261 (vs) & 3144 (vs) & 3195 (vs) & 3251 (vs) & 3262 (vs) & $v_{3}$ \\
\hline & 3378 (vs) & $3392(\mathrm{~s})$ & $3525(w)$ & $3529(w)$ & $3529(w)$ & $v_{4}$ \\
\hline \multirow[t]{5}{*}{3425 (sharp) } & $3415(\mathrm{~s})$ & & & & & $v_{5}$ \\
\hline & $3448(w)$ & $3444(w)$ & $3385(w)$ & $3386(w)$ & $3456(\mathrm{vw})$ & \multirow{2}{*}{$v_{6}$} \\
\hline & & $3456(w)$ & & & & \\
\hline & $3486(\mathrm{vw})$ & 3481 (vw) & 3488 (vw) & $3489(\mathrm{vw})$ & 3489 (vw) & \multirow[b]{2}{*}{$v_{8}$} \\
\hline & $3502(\mathrm{vw})$ & 3498 (vw) & $3505(\mathrm{vw})$ & $3506(\mathrm{vw})$ & $3502(\mathrm{vw})$ & \\
\hline
\end{tabular}

[a] See footnote [a] in Table 1. [b] See mode descriptions in Table 1. [c] $\Delta H_{300}$ values, in $\mathrm{kcalmol}^{-1}$, are relative to the global minimum out-1 (see Table 3). 
Table 3. Experimental and ONIOM (B3LYP/6-31(d):UFF)-calcd vibrational frequencies for the most-stable $[\mathbf{R} \cdot \mathbf{H} \cdot \mathbf{2}]^{+}$structures.

\begin{tabular}{|c|c|c|c|c|c|}
\hline \multirow{2}{*}{$\begin{array}{l}\text { Experiment } \\
{\left[\mathrm{cm}^{-1}\right]}\end{array}$} & \multicolumn{4}{|c|}{ ONIOM (B3LYP/6-31(d):UFF)-calcd frequencies $\left[\mathrm{cm}^{-1}\right]^{[\mathrm{a}]}$} & \multirow[t]{2}{*}{ Mode description $^{[\mathrm{b}}$} \\
\hline & $\operatorname{in}-1(9.1)^{[\mathrm{c}]}$ & in-2 $(12.5)^{[\mathrm{c}]}$ & out $-1(0.0)^{[\mathrm{c}]}$ & out $-2(7.1)^{[\mathrm{c}]}$ & \\
\hline \multirow[t]{4}{*}{$3100-3300$ (broad) } & 3158 (vs) & $3253(\mathrm{~s})$ & $3059(\mathrm{~s})$ & 3184 (vs) & $v_{1}$ \\
\hline & & & $3262(s)$ & 3217 (vs) & $v_{2}$ \\
\hline & 3217 (vs) & 3164 (vs) & 3289 (vs) & 3278 (vs) & $v_{3}$ \\
\hline & 3370 (vs) & $3406(\mathrm{~s})$ & $3532(w)$ & $3534(w)$ & $v_{4}$ \\
\hline \multirow[t]{5}{*}{3425} & $3402(\mathrm{~s})$ & & & & $v_{5}$ \\
\hline & $3449(w)$ & $3438(w)$ & $3381(w)$ & $3385(w)$ & \\
\hline & & $3450(w)$ & & & $v_{6}$ \\
\hline & 3480 (vw) & 3489 (vw) & 3489 (vw) & 3488 (vw) & \multirow[b]{2}{*}{$v_{8}$} \\
\hline & 3500 (vw) & 3493 (vw) & 3505 (vw) & 3506 (vw) & \\
\hline
\end{tabular}

[a] See footnote [a] in Table 1. [b] See mode descriptions in Table 1. [c] See footnote [c] in Table 2.

Table 4. Experimental and ONIOM (B3LYP/6-31(d):UFF)-calculated vibrational frequencies for the moststable $[\mathbf{S} \cdot \mathrm{H} \cdot \mathbf{3}]^{+}$structures.

\begin{tabular}{|c|c|c|c|c|c|c|}
\hline \multirow{2}{*}{$\begin{array}{l}\text { Experiment } \\
{\left[\mathrm{cm}^{-1}\right]}\end{array}$} & \multicolumn{5}{|c|}{ ONIOM (B3LYP/6-31(d):UFF)-calcd frequencies $\left[\mathrm{cm}^{-1}\right]^{[\mathrm{a}]}$} & \multirow{2}{*}{$\begin{array}{l}\text { Mode descrip- } \\
\operatorname{tion}^{[\mathrm{b}]}\end{array}$} \\
\hline & $\begin{array}{l}\text { in- } \\
1(6.3)^{[c]}\end{array}$ & $\begin{array}{l}\text { in-2 } \\
(11.6)^{[\mathrm{c}]}\end{array}$ & $\begin{array}{l}\text { out- } \\
1(7.4)^{[\mathrm{c}]}\end{array}$ & $\begin{array}{l}\text { out }-2 \\
(20.8)^{[c]}\end{array}$ & $\begin{array}{l}\text { out }-3 \\
(22.4)^{[\mathrm{c}]}\end{array}$ & \\
\hline \multirow{4}{*}{$\begin{array}{l}3180-3300 \\
\text { (broad) }\end{array}$} & 3169 (vs) & $3280(\mathrm{~s})$ & 3087 (vs) & 2890 (vs) & 3127 (vs) & $v_{1}$ \\
\hline & & & $3192(\mathrm{~s})$ & $3261(\mathrm{~s})$ & 3204 (s) & $v_{2}$ \\
\hline & 3230 (vs) & 3136 (vs) & 3258 (vs) & $3413(\mathrm{~s})$ & 3275 (vs) & $v_{3}$ \\
\hline & 3377 (vs) & $3392(\mathrm{~s})$ & $3531(w)$ & $3550(w)$ & $3515(w)$ & $v_{4}$ \\
\hline \multirow[t]{5}{*}{3420 (sharp) } & $3403(\mathrm{~s})$ & & & & & $v_{5}$ \\
\hline & $3447(w)$ & $3454(w)$ & $3384(w)$ & $3438(w)$ & $3443(\mathrm{vw})$ & \\
\hline & & $3458(w)$ & & & & $v_{6}$ \\
\hline & $3482(w w)$ & 3482 (ww) & $3488(\mathrm{vw})$ & $3506(\mathrm{vw})$ & $3484(\mathrm{vw})$ & \\
\hline & 3502 (ww) & 3497 (ww) & 3504 (vw) & $3510(\mathrm{vw})$ & $3500(\mathrm{vw})$ & $v_{8}$ \\
\hline
\end{tabular}

[a] See footnote [a] in Table 1. [b] See mode descriptions in Table 1. [c] See footnote [c] in Table 2.

sponding complexes with $\mathbf{R}$ as the host, the $[\mathbf{S} \cdot \mathrm{H} \cdot \mathbf{3}]^{+}$and $[\mathbf{S} \cdot \mathrm{H} \cdot \mathbf{2}]^{+} \quad$ complexes exhibit large differences in their $\mathrm{N}(3) \mathrm{H} \cdots O C$ distances $(\geq 0.1 \AA)$. These findings may be due to repulsive forces between the aglycone oxygen atom of the guest and the aromatic rings of the host $(\mathrm{C}=\mathrm{O} \cdots \pi$ repulsion $)$, which depend on the orientation of the $\mathrm{C}^{\prime}-\mathrm{OH}$ bond in the sugar moiety of the guest (Figure 6).

In compound $\mathbf{3}$, the $\mathrm{C}\left(2^{\prime}\right)-$ $\mathrm{OH}$ bond is oriented in such a way as to allow hydrogen bonding with the aglycone oxygen atom (broken green line in Figure $6 \mathrm{c}, \mathrm{d}$ ) and, thus, to lower its $\mathrm{C}=\mathrm{O} \cdots \pi$ repulsion. No hydrogen-bonding interactions are allowed in compound $\mathbf{2}$ between the aglycone oxygen atom and the $\mathrm{C}\left(2^{\prime}\right)-\mathrm{OH}$ bond because of the unfavorable orientation of the latter moiety. Therefore, the $\mathrm{C}=\mathrm{O} \cdots \pi$ repulsion is more-intense and the $\mathrm{N}(3) \mathrm{H} \cdots O C$ interaction is weaker. Furthermore, Figure 6

phase as kinetically trapped isomers. ${ }^{[3,57]}$ Therefore, it is reasonable to assign the sharp $3425 \mathrm{~cm}^{-1}$ signal (Figure $3 \mathrm{a}, \mathrm{b}$ ) to the in-1 structures of $[\mathbf{R} \cdot \mathrm{H} \cdot \mathbf{2}]^{+}$and $[\mathbf{S} \cdot \mathrm{H} \cdot \mathbf{2}]^{+}$, with the possible contribution from the "out" regioisomers.

The same view applies to the $[\mathbf{S} \cdot \mathbf{H} \cdot \mathbf{3}]^{+}$complex, whose spectrum is qualitatively similar to those of $[\mathbf{R} \cdot \mathrm{H} \cdot 2]^{+}$and $[\mathbf{S} \cdot \mathrm{H} \cdot \mathbf{2}]^{+}$(cf. Figure $3 \mathrm{a}, \mathrm{b}, \mathrm{d}$ ). In contrast, the spectrum of $[\mathbf{R} \cdot \mathrm{H} \cdot \mathbf{3}]^{+}$displays a signal at $3354 \mathrm{~cm}^{-1}$ that has never been observed in the spectra of its isomers (cf. Figure $3 \mathrm{c}$ with Figure 2 and Figure $3 \mathrm{a}, \mathrm{b}, \mathrm{d}$ ). At this point, several questions arise: 1) what is the origin of this new peak, and 2) why is this signal absent in the spectra of all of the $[\mathbf{R} \cdot \mathrm{H} \cdot \mathbf{3}]^{+}$isomers studied (Table 4)?

In Figure 5, the calculated $\mathrm{N}(3)-\mathrm{H} \cdots O C\left(v_{1}\right)$ and symm $\mathrm{H}-\mathrm{N}(4)-\mathrm{H} \cdots \mathrm{OC}\left(v_{3}\right)$ frequencies of the "out" isomers are shown as a function of their corresponding $\mathrm{N}(3) \mathrm{H} \cdots O C$ distances. As expected, the $\mathrm{N}(3)-\mathrm{H} \cdots O C\left(v_{1}\right)$ frequencies decrease with the length of the $\mathrm{N}(3)-\mathrm{H} \cdots O C$ hydrogen bond (Figure 5). This trend is opposite to that of the corresponding symm $\mathrm{H}-\mathrm{N}(4)-\mathrm{H} \cdots O C\left(v_{3}\right)$ frequency. This means that, in the "out" structures, the $\mathrm{N}(3) \mathrm{H} \cdots O C$ interaction is more intense, whereas the $\mathrm{HN}(4) \mathrm{H} \cdots O C$ is less intense. Moreover, Figure 5 shows that, in general, the $\mathrm{N}(3) \mathrm{H} \cdots O C$ bond was stronger in the "out" structures of $[\mathbf{S} \cdot \mathrm{H} \cdot 3]^{+}$(red circles) and $[\mathbf{R} \cdot \mathrm{H} \cdot 3]^{+}$(black circles) than in those of $[\mathbf{S} \cdot \mathrm{H} \cdot 2]^{+}$(blue circles) and $[\mathbf{R} \cdot \mathrm{H} \cdot 2]^{+}$(green circles). Compared to the corre- shows the opposite disposition of the sugar moiety of the guest relative to the aromatic wings of the $\mathbf{R}$ and $\mathbf{S}$ hosts, which may account for the comparatively large difference between the strengths of the $\mathrm{N}(3) \mathrm{H} \cdots O C$ interactions in the complexes with $\mathbf{S}$ as the host.

The plot of Figure 5 explains why the spectra of both the $[\mathbf{R} \cdot \mathrm{H} \cdot \mathbf{2}]^{+}$(Figure $3 \mathrm{a}$ ) and $[\mathbf{S} \cdot \mathrm{H} \cdot \mathbf{2}]^{+}$(Figure $3 \mathrm{~b}$ ) complexes show broad bands peaking at ca. 3190 and ca. $3250 \mathrm{~cm}^{-1}$. The first can be attributed to the $\mathrm{N}(3)-\mathrm{H} \cdots O C\left(v_{1}\right)$ stretching (e.g. the blue and green open circles in Figure 5) and the second to the symm H-N(4)-H $\cdots O C\left(v_{3}\right)$ one (e.g. the blue and green full circles in Figure 5). The $\mathrm{N}(3)-\mathrm{H} \cdots O C\left(v_{1}\right)$ stretching in the $[\mathbf{R} \cdot \mathrm{H} \cdot \mathbf{3}]^{+}$and $[\mathbf{S} \cdot \mathrm{H} \cdot \mathbf{3}]^{+}$structures is located beneath the $C-H$ stretching region $\left(2960-3100 \mathrm{~cm}^{-1}\right.$ ) (the black and red open circles in Figure 5). Instead, the symm $\mathrm{H}-\mathrm{N}(4)-\mathrm{H} \cdots \mathrm{OC}\left(v_{3}\right)$ stretching in $[\mathbf{S} \cdot \mathrm{H} \cdot \mathbf{3}]^{+}$mingles either in the unresolved $3200-3300 \mathrm{~cm}^{-1}$ band (the red full circles at ca. $3250 \mathrm{~cm}^{-1}$ for out-1) or in the $3420 \mathrm{~cm}^{-1}$ peak of its in1 structure (the red full circles at $3413 \mathrm{~cm}^{-1}$ for out-2).

The calculated symm $\mathrm{H}-\mathrm{N}(4)-\mathrm{H} \cdots O C\left(v_{3}\right)$ stretches of the out-1, out-2, and out-5 regioisomers of $[\mathbf{R} \cdot \mathrm{H} \cdot 3]^{+}$also overlapped in the unresolved $3200-3300 \mathrm{~cm}^{-1}$ region (Figure 5, black circles; Table 5). However, the same stretching frequencies in the out-3 and out-4 isomers fall at about $3350 \mathrm{~cm}^{-1}$, that is, in the spectroscopic region in which $[\mathbf{S} \cdot \mathrm{H} \cdot 3]^{+},[\mathbf{R} \cdot \mathrm{H} \cdot \mathbf{2}]^{+}$, and $[\mathbf{S} \cdot \mathrm{H} \cdot \mathbf{2}]^{+}$does not exhibit any signals. 


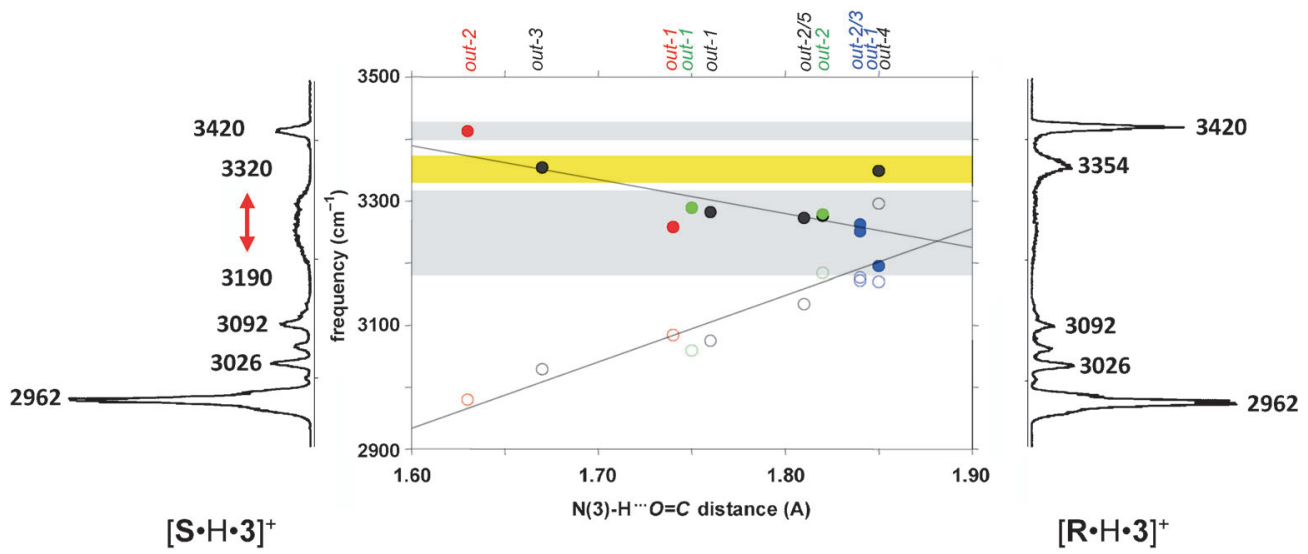

Figure 5. Dependence of the $\mathrm{N}(3)-\mathrm{H} \cdots O C$ ( $v_{1}$; empty circles) and symm $\mathrm{H}-\mathrm{N}(4)-\mathrm{H}$ frequencies ( $v_{3}$; full circles) of the calculated "out" structures of $[\mathbf{R} \cdot \mathrm{H} \cdot 2]^{+}($green $),[\mathbf{S} \cdot \mathrm{H} \cdot 2]^{+}($blue $),[\mathbf{R} \cdot \mathrm{H} \cdot 3]^{+}($black$)$, and $[\mathbf{S} \cdot \mathrm{H} \cdot \mathbf{3}]^{+}($red), as a function of the corresponding N(3)H $\cdots O C$ distance $[\AA]$ : left $)$ IRMPD spectrum of $[\mathbf{S} \cdot \mathbf{H} \cdot \mathbf{3}]^{+}$; right) IRMPD spectrum of $[\mathbf{R} \cdot \mathbf{H} \cdot \mathbf{3}]^{+}$.

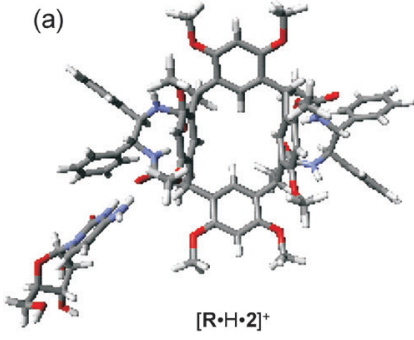

(b)
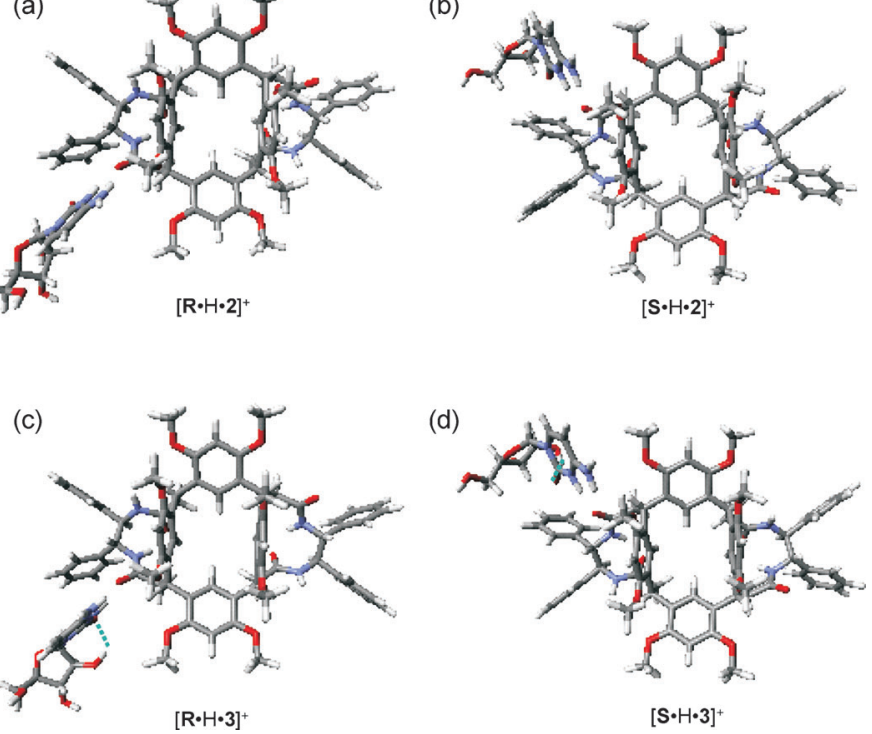

Figure 6. Comparison of the "out" structures of a) $[\mathbf{R} \cdot \mathrm{H} \cdot \mathbf{2}]^{+}$; b) $[\mathbf{S} \cdot \mathrm{H} \cdot \mathbf{2}]^{+}$; c) $[\mathbf{R} \cdot \mathrm{H} \cdot \mathbf{3}]^{+}$; and d) $[\mathbf{S} \cdot \mathrm{H} \cdot \mathbf{3}]^{+}$. Note the opposite disposition of the phenyl rings at the open wings of the $\mathbf{R}$ and $\mathbf{S}$ hosts, the intramolecular $\mathrm{C}\left(2^{\prime}\right) \mathrm{OH} \cdots \mathrm{O}(2)=\mathrm{C}$ bonding (broken green line) in compound $\mathbf{3}$ and its absence in compound $\mathbf{2}$, and the different orientations of the sugar moiety in hosts $\mathbf{R}$ and $\mathbf{S}$ and its effect on the distortion of the proton bonding between the nucleoside and the host amidocarbonyl group.
These assignments confirmed that ESI of methanolic solutions of nucleoside/resorcin[4] arene mixtures generates several co-existing regioisomers of their proton-bound complexes in which the nucleosidic guest was either kinetically trapped inside or outside the host cavity. The strength of the noncovalent interactions in these complexes depends on the possibility of hydrogen-bonding interactions in the nucleoside from the $\mathrm{C}\left(2^{\prime}\right)-\mathrm{OH}$ group and the oxygen atom of the aglycone. The presence of this H-bond moderates the repulsive interactions between the aglycone oxygen atom and the aromatic rings in the host. The frequency of symm $\mathrm{H}-\mathrm{N}(4)-$ $\mathrm{H} \cdots \mathrm{OC}\left(v_{3}\right)$ in the "out" complexes was significantly affected by the subtle interplay among the host/guest attractive and repulsive interactions. Whilst the $v_{3}$ frequencies of the isomers of $[\mathbf{S} \cdot \mathrm{H} \cdot \mathbf{3}]^{+},[\mathbf{S} \cdot \mathrm{H} \cdot \mathbf{2}]^{+}$, and $[\mathbf{R} \cdot \mathrm{H} \cdot \mathbf{2}]^{+}$coalesce into broad bands, those of several "out" $[\mathbf{R} \cdot \mathrm{H} \cdot 3]^{+}$structures were blueshifted from the same region and, therefore, can be discerned.

\section{Conclusion}

Herein, we report the first case of diastereomeric noncovalent complexes that show clearly different IRMPD spectra.

Table 5. Experimental and ONIOM (B3LYP/6-31(d):UFF)-calculated vibrational frequencies for the most-stable $[\mathbf{R} \cdot H \cdot 3]^{+}$structures.

\begin{tabular}{|c|c|c|c|c|c|c|c|c|}
\hline $\begin{array}{l}\text { Experiment } \\
{\left[\mathrm{cm}^{-1}\right]}\end{array}$ & $\operatorname{in}-1(8.7)^{[\mathrm{c}]}$ & in-2 $(10.8)^{[\mathrm{c}]}$ & $\begin{array}{l}\text { DM (B3LYP/6 } \\
\text { out-1 }(0.4)^{[\mathrm{c}]}\end{array}$ & $\begin{array}{l}1(\mathrm{~d}): \mathrm{UFF})-\mathrm{ca} \\
\text { out }-2(5.9)^{[\mathrm{c}]}\end{array}$ & $\begin{array}{l}\text { d frequencies } \\
\text { out }-3(6.9)^{[\mathrm{c}]}\end{array}$ & 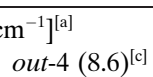 & out-5 $(10.9)^{[\mathrm{c}]}$ & Mode description $^{[\mathrm{b}]}$ \\
\hline \multirow[t]{2}{*}{ 3180-3300 (broad) } & 3171 (vs) & 3251 (s) & 3075 (vs) & 3184 (vs) & 3029 (vs) & $3296(w)$ & 3134 (s) & $v_{1}$ \\
\hline & & & 3253(s) & $3215(\mathrm{~s})$ & $3210(\mathrm{~s})$ & $3252(\mathrm{~s})$ & 3273 (s) & $v_{2}$ \\
\hline \multirow[t]{2}{*}{3354 (broad) } & 3227 (vs) & 3161 (vs) & $3282(\mathrm{~s})$ & 3276 (vs) & $3354(\mathrm{~s})$ & 3349 (vs) & 3255 (vs) & $v_{3}$ \\
\hline & 3374 (vs) & 3407 (s) & $3533(w)$ & $3534(w)$ & $3542(w)$ & $3541(w)$ & $3530(w)$ & $v_{4}$ \\
\hline \multirow[t]{4}{*}{3425 (sharp) } & $3405(\mathrm{~s})$ & & & & & & & $v_{5}$ \\
\hline & $3447(w)$ & $\begin{array}{r}3441(w) \\
3452(w w)\end{array}$ & $3382(w)$ & $3386(w)$ & $3391(w)$ & $3370(w)$ & $3383(w)$ & $v_{6}$ \\
\hline & 3484 (vw) & 3487 (ww) & 3494 (vw) & 3488 (vw) & 3486 (vw) & 3496 (vw) & 3479 (vw) & \multirow[b]{2}{*}{$v_{8}$} \\
\hline & $3502(\mathrm{vw})$ & 3491 (ww) & 3505 (vw) & 3505 (vw) & $3506(\mathrm{vw})$ & 3497 (vw) & 3506 (vw) & \\
\hline
\end{tabular}

[a] See footnote [a] in Table 1. [b] See mode descriptions in Table 1. [c] See footnote [c] in Table 2. 
The complexes are generated in the gas phase by electrospray ionization (ESI) of mixtures that contain a chiral host, that is, pure enantiomers of the bis(diamido)-bridged basket resorcin[4]arene, and achiral and chiral guest molecules, such as cytosine, cytidine, and its epimer, cytarabine. The proton-bound complexes with cytosine as a guest exhibit IRMPD spectra that, in light of ONIOM (B3LYP/631(d):UFF) calculations, are consistent with the occurrence of several isomeric structures, in which the N(3)-protonated guest is either accommodated inside the host cavity (the "in" structure) or outside it (the "out" structure). A similar picture was observed for the ESI-formed diastereomeric proton-bound complexes with cytidine and cytarabine as guests. However, the complex between cytarabine and the $R, R, R, R$-enantiomer of the host shows a spectroscopic pattern that is clearly different from the others. This difference is attributed to the effects of the intramolecular hydrogen bonding between the $\mathrm{C}\left(2^{\prime}\right)-\mathrm{OH}$ group and the aglycone oxygen atom of the nucleosidic guest upon repulsive interactions between the same oxygen atom and the aromatic rings of the host.

\section{Experimental Section}

Chemicals: Enantiomerically pure basket resorcin[4]arenes $\mathbf{R}$ and $\mathbf{S}$, in their flattened-cone conformation, were synthesized and purified according to literature procedures. ${ }^{[39]}$ Compounds 1-3 were purchased from a commercial source and used without further purification.

IRMPD spectroscopy: All of the proton-bound complexes were generated in a modified Bruker Esquire 6000 quadrupole ion trap by electrospray ionization (ESI) of methanolic mixtures of the basket resorcin[4]arene and the nucleoside. The IR beam was focused in the ion trap through a conical hole in the ring electrode. IR spectroscopy in the range $\tilde{v}=$ $2800-3600 \mathrm{~cm}^{-1}$ was performed by using an IR optical parametric oscillator/amplifier (OPO/OPA) system that was pumped by a $10 \mathrm{~Hz} \mathrm{Nd:YAG}$ laser $(650 \mathrm{~mJ}$ per pulse, $8 \mathrm{~ns}$ pulse duration). The typical output energy over this wavelength range was about $23 \mathrm{~mJ}$ per pulse with a spectroscopic band-width of about $5 \mathrm{~cm}^{-1}$. 58$]$

Computational details: All of the calculations on the noncovalent adducts between the $\mathbf{R}$ and $\mathbf{S}$ hosts and the O- and N-protonated guests 1-3 were performed by using the hybrid quantum-mechanics/molecular-mechanics (QM/MM) ONIOM method, ${ }^{[59]}$ as implemented in the Gaussian 03 package. ${ }^{[45]}$ The $\mathrm{QM}$ region, which included both the $\mathrm{CO}-\mathrm{NH}-$ $\mathrm{CH}-\mathrm{CH}-\mathrm{NH}-\mathrm{CO}$ sequences of the host and the entire protonated guest, was calculated by using the DFT B3LYP functional ${ }^{[43]}$ and the $6-31 \mathrm{G}(\mathrm{d})$ basis set. ${ }^{[60]}$ The rest of the host molecule constituted the MM region, for which the UFF force field ${ }^{[61]}$ was used. All of the ONIOM(B3LYP/6$31 \mathrm{G}^{*}: \mathrm{UFF}$ ) geometry-optimizations were full, without restrictions, and the stationary points were characterized as true minima by vibrational analysis. The value 0.961 was used as a scaling factor for the calculated harmonic frequencies.

\section{Acknowledgements}

This work was supported by the Ministero dell'Istruzione dell'Università e della Ricerca (MIUR-PRIN 2007H9S8SW-FIRB contract number RBPR05NWWC 003), by an FIRB grant (No. RBPR05NWWC 006) from the Sapienza Università di Roma, Italy (Funds for Selected Research Topics 2008-2010), and by the Fondazione Roma (Roma, Italy). Andrea Tafi is gratefully acknowledged for computational support and
Annito Di Marzio is acknowledged for technical assistance. We are also grateful to CASPUR (Consorzio interuniversitario per le Applicazioni di Supercalcolo Per Università e Ricerca, via dei Tizii 6b - Rome 00185, Italy) for the availability of computational resources.

[1] R. Bentley, Archiv. Biochem. Biophys. 2003, 414, 1-12.

[2] V. Davankov, Chirality 1997, 9, 99-102.

[3] M. Sawada, J. Mass Spectrom. Soc. Jpn. 1997, 45, 439-458.

[4] W. Shen, P. S. H. Wong, R. G. Cooks, Rapid Commun. Mass Spectrom. 1997, 11, 71-74.

[5] W. Tao, D. Zhang, F. Wang, P. D. Thomas, R. G. Cooks, Anal. Chem. 1999, 71, 4427-4429.

[6] A. Filippi, A. Giardini, S. Piccirillo, M. Speranza, Int. J. Mass Spectrom. 2000, 198, 137-163.

[7] D. V. Dearden, Y. Liang, J. B. Nicoll, K. A. Kellersberger, J. Mass Spectrom. 2001, 36, 989-997.

[8] C. A. Schalley, Mass Spectrom. Rev. 2002, 21, 253-309.

[9] M. Sawada, J. Mass Spectrom. Soc. Jpn. 2002, 50, 311-329.

[10] W. A. Tao, R. G. Cooks, Anal. Chem. 2003, 75, 25A.

[11] M. Shizuma, J. Mass Spectrom. Soc. Jpn. 2003, 51, 330-333.

[12] M. Speranza, Adv. Phys. Org. Chem. 2004, 39, 147-281.

[13] M. Speranza, Int. J. Mass Spectrom. 2004, 232, 277-317.

[14] K. A. Schug, W. Lindner, J. Sep. Sci. 2005, 28, 1932-1955.

[15] M. Speranza, M. Satta, S. Piccirillo, F. Rondino, A. Paladini, A. Giardini, A. Filippi, D. Catone, Mass Spectrom. Rev. 2005, 24, $588-$ 610

[16] A. Di Tullio, S. Reale, F. De Angelis, J. Mass Spectrom. 2005, 40, $845-865$.

[17] S. C. Nanita, R. G. Cooks, Angew. Chem. 2006, 118, 568-583; Angew. Chem. Int. Ed. 2006, 45, 554-569.

[18] A. Zehnacker, M. A. Suhm, Angew. Chem. 2008, 120, 7076-7100; Angew. Chem. Int. Ed. 2008, 47, 6970-6992.

[19] M. Speranza, F. Rondino, M. Satta, A. Paladini, A. Giardini, D. Catone, S. Piccirillo, Chirality 2009, 21, 119-144.

[20] M. Speranza, F. Gasparrini, B. Botta, C. Villani, D. Subissati, C. Fraschetti, F. Subrizi, Chirality 2009, 21, 69-86.

[21] Wijeratne, K. A. Schug, J. Sep. Sci. 2009, 32, 1537-1547.

[22] M. Vairamani, S. Kumari, in Chiral Recognition in the Gas Phase, (Ed. A. Zehnacker) CRC Press, Taylor \& Francis, Boca Raton, FL, USA, 2010, pp. 143-166.

[23] V. Dearden, N. Fang, in Chiral Recognition in the Gas Phase, (Ed. A. Zehnacker) CRC Press, Taylor \& Francis, Boca Raton, FL, USA, 2010, pp. 133-142.

[24] M. Speranza, in Chiral Recognition in the Gas Phase, (Ed. A. Zehnacker) CRC Press, Taylor \& Francis, Boca Raton, FL, USA, 2010 pp. $87-131$.

[25] Y. M. E. Fung, T. Besson, J. Lemaire, P. Maitre, R. A. Zubarev, Angew. Chem. 2009, 121, 8490-8492; Angew. Chem. Int. Ed. 2009, 48, 8340-8342.

[26] N. C. Polfer, J. J. Valle, D. T. Moore, J. Oomens, J. R. Eyler, B. Bendiak, Anal. Chem. 2006, 78, 670-679.

[27] R. C. Dunbar, J. D. Steill, J. Oomens, J. Am. Chem. Soc. 2011, 133, 1212-1215.

[28] M. Peiris, J. M. Riveros, J. R. Eyler, Int. J. Mass Spectrom. 1996, 159, $169-183$.

[29] J. J. Valle, J. R. Eyler, J. Oomens, D. T. Moore, A. F. G. van der Meer, G. von Helden, G. Meijer, C. L. Hendrickson, A. G. Marshall, G. Blakney, Rev. Sci. Instrum. 2005, 76, 023103/1-023103/7.

[30] G. von Helden, D. van Heijnsbergen, G. Meijer, J. Phys. Chem. A 2003, 107, 1671-1688.

[31] D. T. Moore, J. Oomens, J. R. Eyler, G. von Helden, G. Meijer, R. C. Dunbar, J. Am. Chem. Soc. 2005, 127, 7243-7254.

[32] P. Martre, S. Le Caer, A. Simons, W. Jones, J. Lemaire, H. Mestdag, M. Heninger, G. Mauclaire, P. Boissel, R. Prazeres, F. Glotin, J. M. Ortega, Nucl. Instrum. Methods Phys. Res. Sect. A 2003, 507, 541546. 
[33] X. L. Kong, I. A. Tsai, S. Sabu, C. C. Han, Y. T. Lee, H. C. Chang, S. Y. Tu, A. H. Kung, C. C. Wu, Angew. Chem. 2006, 118, 42364240; Angew. Chem. Int. Ed. 2006, 45, 4130-4134.

[34] A. Kamariotis, O. V. Boyarkin, S. R. Mercier, R. D. Beck, M. F. Bush, E. R. Williams, T. R. Rizzo, J. Am. Chem. Soc. 2006, 128, 905-916.

[35] T. D. Vaden, T. S. J. A. de Boer, J. P. Simons, L. C. Snoek, Phys. Chem. Chem. Phys. 2008, 10, 1443-1447.

[36] R. Wu, T. B. McMahon, J. Phys. Chem. B 2009, 113, 8767-8775.

[37] As a matter of fact, some IRPD spectroscopic studies on protonbound amino-acid adducts have been carried out by Chang and coworkers groups (see reference [33]) and by McLafferty and co-workers; see: H. B. Oh, C. Lin, H. Y. Hwang, H. Zhai, K. Breuker, V. Zabrouskov, B. C. Carpenter, F. W. McLafferty, J. Am. Chem. Soc. 2005, 127, 4076-4083; X. Kong, C. Lin, G. Infusini, H. B. Oh, H. Jiang, K. Breuker, C. C. Wu, O. P. Charkin, H. C. Chang, F. W. McLafferty, ChemPhysChem 2009, 10, 2603-2606. However, no spectroscopic differences between the diastereomeric complexes were reported in these studies.

[38] Very recently, an IRMPD study on the protonated dimers of Cinchona alkaloids by Zehnacker and co-workers revealed small differences in the intensities of the $v(\mathrm{OH})$ stretches, which were attributed to the presence of a weak $\mathrm{CH}$.. O interaction on the neutral part of the heterochiral complex; see: D. Scuderi, K. Le Barbu-Debus, A. Zehnacker, Phys. Chem. Chem. Phys. 2011, 13, 17916-17929).

[39] B. Botta, I. D'Acquarica, L. Nevola, F. Sacco, Z. Valbuena Lopez, G. Zappia, C. Fraschetti, M. Speranza, A. Tafi, F. Caporuscio, M. C. Letzel, J. Mattay, Eur. J. Org. Chem. 2007, 5995-6002.

[40] B. Botta, C. Fraschetti, I. D'Acquarica, F. Sacco, J. Mattay, M. C. Letzel, M. Speranza, Org. Biomol. Chem. 2011, 9, 1717-1719.

[41] B. Botta, A. Tafi, F. Caporuscio, M. Botta, L. Nevola, I. D'Acquarica, C. Fraschetti, M. Speranza, Chem. Eur. J. 2008, 14, 3585-3595.

[42] J. M. Bakker, J. Y. Salpin, P. Maitre, Int. J. Mass Spectrom. 2009, $283,214-221$

[43] C. Lee, W. Yang, R. Parr, Phys. Rev. B 1988, 37, 785-789.

[44] A. D. Becke, J. Chem. Phys. 1993, 98, 5648-5652.

[45] Gaussian 03, M. J., Frisch, G. W. Trucks, H. B. Schlegel, G. E. Scuseria, M. A. Robb, J. R. Cheeseman, J. Montgomery, T. Vreven, K. N. Kudin, J. C. Burant, J. M. Millam, S. S. Iyengar, J. Tomasi, V. Barone, B. Mennucci, M. Cossi, G. Scalmani, N. Rega, G. A. Petersson, H. Nakatsuji, M. Hada, M. Ehara, K. Toyota, R. Fukuda, J. Hasegawa, M. Ishida, T. Nakajima, Y. Honda, O. Kitao, H. Nakai, M. Klene, X. Li, J. E. Knox, H. P. Hratchian, J. B. Cross, V. Bakken, C. Adamo, J. Jaramillo, R. Gomperts, R. E. Stratmann, O. Yazyev, A. J. Austin, R. Cammi, C. Pomelli, J. W. Ochterski, JP. Y. Ayala, K. Morokuma, G. A. Voth, P. Salvador, J. J. Dannenberg, V. G. Zakrzewski, S. Dapprich, A. D. Daniels, M. C. Strain, O. Farkas, D. K. Malick, A. D. Rabuck, K. Raghavachari, J. B. Foresman, J. V. Ortiz,
Q. Cui, QA. G. Baboul, S. Clifford, J. Cioslowski, B. B. Stefanov, G. Liu, A. Liashenko, P. Piskorz, I. Komaromi, R. L. Martin, D. J. Fox, T. Keith, M. A. Al-Laham, C. Y. Peng, A. Nanayakkara, M. Challacombe, P. M. W. Gill, B. Johnson, W. Chen, M. W. Wong, C. Gonzalez, J. A. Pople. Gaussian, Inc., Wallingford CT, 2004..

[46] J. Y. Salpin, S. Guillaumont, J. Tortajada, L. MacAleese, J. Lemaire, P. Maitre, ChemPhysChem 2007, 8, 2235-2244.

[47] see Ref. [42].

[48] A. Filippi, C. Fraschetti, L. Guidoni, F. Rondino, S. Piccirillo, V. Steinmetz, M. Speranza, J. Am. Chem. Soc, manuscript submitted

[49] B. Botta, C. Fraschetti, F. R. Novara, A. Tafi, F. Sacco, L. Mannina, A. P. Sobolev, J. Mattay, M. C. Letzel, M. Speranza, Org. Biomol. Chem. 2009, 7, 1798-1806.

[50] J. M. Bakker, R. K. Sinha, T. Besson, M. Brugnara, P. Tosi, J. Y. Salpin, P. Maitre, J. Phys. Chem. A 2008, 112, 12393-12400.

[51] J. R. Roscioli, L. R. McCunn, M. A. Johnson, Science 2007, 316 , 249-254.

[52] J. S. Prell, M. Demireva, J. Oomens, E. R. Williams, J. Am. Chem. Soc. 2009, 131, 1232-1242.

[53] J. Oomens, J. D. Steill, B. Redlich, J. Am. Chem. Soc. 2009, 131, 4310-4319.

[54] J. S. Prell, T. M. Chang, J. A. Biles, G. Berden, J. Oomens, E. R. Williams, J. Phys. Chem. A 2011, 115, 2745-2751.

[55] P. Hurtado, F. Gamez, S. Hamad, B. Martinez-Haya, J. D. Steill, J. Oomens, J. Phys. Chem. A 2011, 115, 7275-7282.

[56] J. Oomens, B. G. Sartakov, G. Meijer, G. von Helden, Int. J. Mass Spectrom. 2006, 254, 1-19.

[57] J. D. Steill, J. Oomens, J. Am. Chem. Soc. 2009, 131, 13570-13571.

[58] J. Lemaire, P. Boissel, M. Heninger, G. Mauclaire, G. Bellec, H. Mestdagh, A. Simon, S. L. Caer, J. M. Ortega, F. Glotin, P. Maitre, Phys. Rev. Lett. 2002, 89, 273002.

[59] a) F. Maseras, K. Morokuma, J. Comput. Chem. 1995, 16, 11701179; b) S. Humbel, S. Sieber, K. Morokuma, J. Chem. Phys. 1996, 105, 1959-1967; c) M. Svensson, S. Humbel, R. D. J. Froese, T. Matsubara, S. Sieber, K. Morokuma, J. Phys. Chem. 1996, 100, $19357-$ 19363; d) M. Svensson, S. Humbel, K. Morokuma, J. Chem. Phys. 1996, 105, 3654-3661; e) S. Dapprich, I. Komromi, K. S. Byun, K. Morokuma, M. J. Frisch, J. Mol. Struct. 1999, 474-515, 1-21.

[60] a) M. M. Francl, W. J. Pietro, W. J. Hehre, J. S. Binkley, M. S. Gordon, D. J. Defrees, J. A. Pople, J. Chem. Phys. 1982, 77, 36543665; b) W. J. Hehre, R. Ditchfield, J. A. Pople, J. Chem. Phys. 1972, 56, 2257-2261; c) P. C. Hariharan, J. A. Pople, Theor. Chim. Acta 1973, 28, 213-222.

[61] A. K. Rappe, C. J. Casewit, K. S. Colwell, W. A. Goddard III, W. M. Skiff, J. Am. Chem. Soc. 1992, 114, 10024-10035.

Received: February 24, 2012 Published online: June 13, 2012 